\title{
Juventude e saúde: análise do discurso sobre oferta e acesso aos equipamentos e serviços públicos
}

\author{
Youth and health: discourse analysis on supply and access to public facilities
} Juventud y salud: análisis del discurso sobre la oferta y el acceso a los servicios públicos

\author{
Cinoélia Leal Souza', Raquel Souzas" \\ ' Centro Territorial de Educação Profissional de Vitória da Conquista. Vitória da Conquista-BA, Brasil. \\ Universidade Estadual de Santa Cruz, Curso de Mestrado em Desenvolvimento Regional \\ e Meio Ambiente (Mestranda). Santa Cruz-BA, Brasil. \\ " Universidade Federal da Bahia, Instituto Multidisciplinar de Saúde, Campus Anísio Teixeira. \\ Vitória da Conquista-BA, Brasil.
}

Submissão: 04-03-2011 Aprovação: 28-11-2012

\begin{abstract}
RESUMO
Do ponto de vista sociodemográfico, os jovens constituem hoje importante parcela da população brasileira. Em 2005 o governo brasileiro publicou a Política Nacional da Juventude. Apesar disso, os jovens ainda encontram muitas dificuldades de acesso aos serviços públicos, sobretudo os de saúde. Este estudo objetivou analisar o discurso de jovens e adolescentes estudantes sobre as condições de acesso aos serviços públicos e de saúde por meio da pesquisa qualitativa. Os estudantes abordados residem na zona rural e urbana do município de Vitória da Conquista - Bahia. Foi utilizado o método análise de conteúdo, proposto por Bardin (1979) e Minayo (2006), e a técnica de grupos de discussão para juventude proposta por Weller (2006).

Descritores: Juventude; Estudantes; Acesso aos Serviços de Saúde; Pesquisa Qualitativa.
\end{abstract}

ABSTRACT
From the standpoint of sociodemographic, teens today represent an important portion of the Brazilian population. In 2005 the Brazilian government published the National Youth Policy. Despite of this, many teens still find difficulties in accessing public services, especially the ones involving health. This study aimed to analyze young students' speeches about the conditions of access to public services and health through qualitative research. The students inquired live in rural and urban areas of the city of Vitória da Conquista - Bahia. The method used was the content analysis proposed by Bardin (1979) and Minayo (2006), and the technique of discussion groups for youth proposed by Weller (2006).

Key words: Youth; Students; Health Services Accessibility; Qualitative Research.

\section{RESUMEN}

Desde el punto de vista socio-demográfico los adolescentes hoy son parte importante de la población brasileña. En 2005, el gobierno brasileño publicó la Política Nacional de la Juventud. A pesar de esto, muchos jóvenes todavía encuentran dificultades para acceder a los servicios públicos, especialmente los de salud. Este estudio tuvo como objetivo analizar el discurso de los jóvenes sobre las condiciones de acceso a los servicios públicos y de salud a través de la investigación cualitativa. Los estudiantes enfocados residen en zonas rurales y urbanas del municipio de Vitória da Conquista, en el estado de la Bahia, en Brasil. El método utilizado fue el análisis de contenido propuesto por Bardin (1979) y Minayo (2006), y la técnica de grupos de discusión para la juventud propuesta por Weller (2006).

Palabras clave: Juventud; Estudiantes; Accesibilidad a los Servicios de Salud; Investigación Cualitativa. 


\section{INTRODUÇÃO}

A juventude é uma etapa muito importante da vida e destaca-se nas discussões no meio científico e social devido à singularidade que adquiriu na contemporaneidade. A juventude não pode ser caracterizada apenas por uma definição de faixa etária, contudo a adoção de um critério cronológico faz-se necessária para a identificação de requisitos que orientem a investigação do tipo epidemiológica e a elaboração de estratégias e políticas de saúde pública ${ }^{(1)}$. A classificação etária serve apenas como um parâmetro social para o reconhecimento político da fase juvenil, servindo como uma referência imprescindível e genérica para a elaboração de políticas públicas ${ }^{(2)}$.

A Política Nacional da Juventude caracteriza a juventude como uma condição social, parametrizada por uma faixa etária, que no Brasil congrega cidadãos e cidadãs com idade compreendida entre os 15 e os 29 anos. Sendo tema de interesse público, a condição juvenil deve ser tratada sem estereótipos e a consagração dos direitos dos/das jovens precisa partir da própria diversidade que caracteriza a(s) juventude(s) ${ }^{(2)}$.

Já a adolescência pode ser definida como a etapa da vida que é compreendida entre a infância e a fase adulta, marcada por um complexo processo de crescimento e desenvolvimento biopsicossocial. A Organização Mundial da Saúde caracteriza a adolescência como a segunda década de vida, entre o período de 10 a 19 anos de idade. Já a Lei $n^{\circ} 8.069 / 90$ que dispõe sobre o Estatuto da Criança e do Adolescente (ECA), diz que adolescente é a pessoa entre 12 e 18 anos de idade ${ }^{(2)}$.

Em 2009, o Brasil tinha um total de quase 80 milhões de crianças, adolescentes e jovens até 24 anos (cerca de $42 \%$ do total da população). As famílias que tinham pelo menos um membro na faixa etária de 0 a 24 anos representavam, em 2009, 2/3 das famílias brasileiras. No estado da Bahia 18,5\% das famílias possuem adolescentes de 10 a 19 anos de idade. Nesse número, o percentual de famílias consideradas pobres (com rendimento mensal per capita de até $1 / 2$ salário mínimo) era de aproximadamente $40, \%{ }^{(3)}$. Esses dados refletem a necessidade de políticas públicas de saúde voltadas para os adolescentes, uma vez que suas famílias, marcadas pela vulnerabilidade socioeconômica, buscam nos serviços públicos a atenção e o atendimento a sua saúde.

Os jovens e adolescentes somam uma parcela importante da população brasileira, mas, no que se refere especificamente à saúde, foi somente em 1989 que o Ministério da Saúde criou um programa de saúde que mais se aproximava desse grupo, o Programa de Saúde do Adolescente (PROSAD) $)^{(4)}$. As ações do PROSAD baseiam-se na promoção à saúde, na identificação de grupos vulneráveis, na detecção precoce de doenças e agravos, no tratamento adequado, na reabilitação e inserção social ${ }^{(5)}$.

Em relação a políticas públicas para a juventude, somente em 2005 foram fortalecidas as discussões sobre uma Política Nacional da Juventude, com a Criação do Conselho Nacional de Juventude (Conjuve), orientado pela Lei $n^{\circ} 11.129 / 2005$ e regulamentado pelo Decreto Presidencial $n^{\circ} 5.490$ de 14 de julho de 2005. O Conjuve tem seu trabalho pautado e direcionado à proposição e avaliação das políticas públicas de juventude, especialmente as executadas pelo Executivo Federal. No ano seguinte, em 2006, foi publicada no Brasil a Política Nacional da Juventude, que vem contribuindo para a inserção da temática juventude nas discussões e proposição de políticas públicas direcionadas aos jovens ${ }^{(2)}$.

O município de Vitória da Conquista, localizado no sudoeste da Bahia, possui aproximadamente 306.866 habitantes $^{(6)}$, dos quais 55.136 estão entre 10 a 19 anos de idade. O Município conta com 29 escolas de ensino médio, das quais 18 são escolas públicas estaduais, uma é pública federal e 10 são estabelecimentos de ensino privados ${ }^{(7)}$. Em 2009, dos 13.759 estudantes de Vitória da Conquista matriculados nas escolas de ensino médio, 11.816 estavam em escolas públicas estaduais, 369 em escola pública federal e 1.574 em escolas particulares $^{(6)}$. Tais números comprovam a predominância de escolares adolescentes nas instituições de ensino públicas.

Diante da importância da aplicação de políticas públicas de saúde voltadas para os jovens e de conhecer como estes têm vivenciado essas políticas, o presente estudo tem por objetivo analisar o discurso de jovens e adolescentes estudantes da rede pública de ensino de Vitória da Conquista, das zonas rural e urbana, sobre as condições de acesso aos equipamentos públicos e de saúde.

\section{METODOLOGIA}

Estudo exploratório, descritivo, de abordagem qualitativa, que, segundo Minayo (2007), é o método que se aplica ao estudo da história, das relações, das representações, das crenças, das percepções e das opiniões que os seres humanos fazem a respeito de como vivem, constroem seus artefatos e a si mesmos, sentem e pensam ${ }^{(8)}$.

Integra o projeto "Perfil identitário da juventude de Vitória da Conquista (Sudoeste da Bahia): estudo comparativo da rede pública de ensino", registrado no Instituto Multidisciplinar de Saúde - Campus Anísio Teixeira da Universidade Federal da Bahia. O projeto foi aprovado pelo Comitê de Ética da Secretaria de Saúde do Estado da Bahia, sob o protocolo CAAE 0120.0.053.000-08, como previsto na resolução 196/96 do Conselho Nacional de Saúde que regulamenta as pesquisas com seres humanos.

Como parte do projeto mencionado foram preenchidos formulários semiestruturados com informações sociodemográficas que apontavam características do grupo, tais como idade, sexo, hábitos alimentares, meios de acesso a saúde e comunicação. Tais dados auxiliaram na compreensão do contexto do grupo e de produção dos discursos. Foram entrevistados 143 estudantes, 93 do sexo feminino e 50 do masculino; 73 viviam na área urbana e 70 na área rural. Com relação à idade, 79 tinham 18 anos, 46 entre 18 e 24 anos, e 15 dos residentes na área rural estavam com idade acima de 25 anos. Todos estudavam num mesmo complexo escolar, com estruturas de funcionamento descentralizadas na área rural e urbana. O número de entrevistados não é representativo dos estudantes em geral, residentes em Vitória da Conquista/BA, já que se trata de uma amostra por conveniência. Tais números foram analisados estatisticamente e auxiliaram na construção do roteiro 
de entrevista e dos grupos de discussão, bem como direcionaram o olhar das pesquisadoras para os equipamentos públicos mais acessados pelos estudantes.

Na etapa qualitativa, foram selecionados previamente adolescentes que em geral estavam com idade entre 12 e 18 anos, como estabelecido no ECA, estudantes de escolas públicas localizadas nas zonas rural e urbana do município de Vitória da Conquista, no estado da Bahia. Entretanto, na pesquisa nem sempre foi possível manter o critério de idade estabelecido nos documentos oficiais, em razão de haver descompasso entre idade escolar e idade biológica.

Foram realizados dois grupos de discussão com os jovens e adolescentes da rede pública de ensino de Vitória da Conquista, um em uma escola da zona urbana do município e outro na zona rural. O grupo realizado na zona urbana contou com 17 participantes, predominantemente do sexo feminino, do terceiro ano do ensino médio. O grupo realizado na zona rural 20 vinte participantes de ambos os sexos, estudantes do segundo ano do ensino médio.

Os grupos foram orientados por um roteiro de discussão. Essa estratégia de pesquisa privilegia as interações e proporciona uma maior inserção do pesquisador no universo dos sujeitos $^{(9)}$. Foram realizados dois grupos de discussão e entrevistas com representantes do corpo estudantil de cada grupo. As entrevistas foram gravadas com a devida autorização e posteriormente transcritas para análise. Após a realização dos grupos de discussão e das entrevistas, seguiu-se a organização e sistematização da análise dos dados obtidos ${ }^{(10,8)}$.

A partir de informações do grupo foi realizada etnografia dos lugares de saúde mencionados pelos participantes, buscou-se estabelecer uma interlocução com os espaços públicos utilizados com mais frequência e citados pelos estudantes. A etnografia foi a melhor forma de conhecer esses espaços. Por meio da observação etnográfica foi possível visualizar e compreender com mais profundidade situações mencionadas pelos entrevistados, compreender as diferentes dimensões da questão. A etnografia é uma prática fundamentalmente antropológica e visa obter informações a partir da interação direta no campo de estudo. E nosso caso, o período de observação durou em média uma semana (RAP- Rapid assement procedures) ${ }^{(11)}$.

Após a sistematização e análise dos discursos foi possível a elaboração da etapa de análise com a construção de categorias específicas, categorias gerais e núcleos estruturadores dos significados dos discursos ${ }^{(8,10)}$.

\section{RESULTADOS}

A. Significados para a experiência escolar: "entre a vida escolar e as demandas da vida" (estudantes das áreas urbana e rural)

Em relação à percepção dos jovens estudantes sobre a vida escolar, foi possível perceber que a escola é vista como um local de interação entre os jovens e que para alguns é um ambiente de superação de dificuldades. A falta de infraestrutura na escola, além de ser um fator que preocupa os adolescentes, prejudica o desenvolvimento do escolar.
Quando eu cheguei aqui já tinha começado no ano passado, já tinha começado o ano letivo, já tinha terminado a primeira unidade, e...ai eu cheguei já pegando praticamente o bonde andando, tive dificuldades em alguma matéria, mais graças a Deus o primeiro ano foi superado (estudante - zona urbana de VC).

As condições do espaço não são muito agradáveis, o piso. (...) colocaria uns banquinhos no pátio (estudante - zona rural de VC).

No espaço urbano revelam-se discursos marcados pela superação de dificuldades e adaptação às demandas da vida para a conquista da escolaridade almejada. Nesse contexto, o descompasso entre a idade biológica/cronológica e a idade escolar é um problema concreto com o qual os/as estudantes tem que lidar.

B. Significados para a vida em comunidade: "viver em lugares onde tudo é ausência" (urbano) e "Viver em um lugar tranqüilo, porém com dificuldade de acesso aos serviços básicos" (rural)

Para os participantes dos grupos estudados a comunidade onde residem apresenta muitas carências de infraestrutura e a violência é algo próximo aos jovens. Essa proximidade dos adolescentes com situações de violência foi apontada em outro estudo(12), o qual traz a informação que dentre os jovens pesquisados, 30\% já haviam visto alguém morrer de forma violenta, $15 \%$ já haviam sido assaltados e 70\% já tivera contato com arma de fogo alguma vez na vida.

Não moro perto. Moro no Xx... lá é muito ruim...cheio de buracos, só tem poeira lá (estudante - zona urbana de VC).

\section{Só tem ladrão lá. (estudante - zona urbana de VC).}

Não vou dizer que não é perigoso, mas lá também tem muita gente honesta. (estudante - zona urbana de VC).

A proximidade de situações de violência foi mais enfatizada nas áreas urbanas. A zona rural ainda se apresenta como um local mais seguro para os jovens.

Eu também moro em um bairro afastado (...), é um bairro tranquilo, porque na verdade nem sei se é considerado bairro ainda, ele é um povoado, com algumas famílias, um assentamento. (estudante - zona rural de VC).

Aqui é um lugar tranqüilo, sossegado, você pode ficar a vontade sem medo (estudante - zona rural de VC).

A violência que atinge crianças e adolescentes na realidade brasileira é muito importante e deve mobilizar todos os setores da sociedade, sendo reconhecida como problema relevante de saúde pública ${ }^{(13)}$, sendo objeto de reflexão por parte de várias áreas do saber, entre elas a Saúde Pública, pelo papel que assume diante da morbi-mortalidade, vitimizando crianças, jovens, adultos e idosos indiscriminadamente ${ }^{(14)}$. 
Segundo a Pesquisa Nacional de Saúde do Escolar (PenSE) de 2007, a proporção de escolares que deixam de ir à escola por não se sentirem seguros no caminho de casa para a escola ou da escola para casa foi de $6,4 \%$, no total das capitais brasileiras e no Distrito Federal ${ }^{(15)}$. Isso indica que a violência vivenciada pelos jovens e adolescentes tem prejudicado a convivência na comunidade, a construção de laços de amizades e a relação entre amigos, vizinhos e colegas de escola, que são relações imprescindíveis do cotidiano das pessoas. A identificação e o estudo da violência é um dos passos necessários ao entendimento social e uma etapa na luta para diminuir o peso desta problemática na sociedade ${ }^{(16)}$.

A ausência de espaços de interação faz da escola um lugar privilegiado para encontrar amigos, notadamente no espaço rural. Ao serem questionados sobre os lugares de "paquera", poucos adolescentes mencionaram locais de encontro e o único local citado foi a praça.

[ silêncio] Eu gosto do domingo (...) a gente se conhece, namora (...) na praça. (estudante - zona rural de VC).

C. Significados para a gravidez no ambiente escolar: "entre a incompreensão das estruturas institucionais escolares e o apoio dos amigos" (urbano) e "Dificuldade em expressar opinião em um ambiente que deveria exercitar a liberdade de expressão" (rural)

A juventude é um período da vida em que ocorrem muitas mudanças, o crescimento rápido, em que o surgimento das características sexuais secundárias, a conscientização da sexualidade, a estruturação da personalidade e a adaptação ambiental e integração social são as principais mudanças ${ }^{(17)}$. Tema recorrente e importante quando se fala em mudanças e sexualidade na adolescência, a gravidez na adolescência é considerada em alguns países um problema de saúde pública, pois pode implicar complicações obstétricas, bem como problemas psicossociais e econômicos.

Nos grupos de discussão realizados a gravidez na adolescência e sua relação com o ambiente escolar foi descrita como uma etapa de dificuldade, principalmente pelo despreparo de professores e funcionários da escola em conduzir tal situação.

No caso de roupa mesmo, não podia vir de roupa de cor (...) não podia ser calça de malha, um dia eu vim com uma calça florada de malha, a diretora falou que eu não podia vir assim na escola, nem de sandália... ai depois de discutir liberaram. (estudante - zona urbana de VC).

Liberou porque criticaram muito, pois uma gestante incha, né? Fica sensível e tudo e estava ocorrendo assim, as meninas estavam ficando chateadas na sala por conta de serem barradas e não poderem entrar de chinelo. (estudante - zona urbana de VC).

X. mesmo foi barrada uma época porque estava de chinelo, com o pé inchado. Não estavam olhando o lado da situação do aluno, do aluno querer estudar e encontrar essas barreiras. (estudante - zona urbana de VC).
(...) com o passar do tempo foram aceitando, mesmo por que se não aceitar ia ocorrer o quê? Agente ia... as meninas iam acabar desistindo do curso... estava com o que? com quatro grávidas na sala, não foi? Né... de quatro uma desistiu. (estudante - zona urbana de VC).

Percebe-se nessas falas que existe uma incompreensão em relação à gravidez por parte dos funcionários da escola e que isso ocasiona desânimo das estudantes em continuar os estudos durante a gravidez. Já a reação com colegas de escola é diferente, as estudantes relatam que existe apoio dos colegas e que se sentem bem com eles.

Eu adorava quando vinha pra escola, porque em casa estava aquele clima meio pesado, assim, minha mãe ela na hora brigou comigo, mas ela ficou chateada, porque ela conversava comigo sobre essas coisas (sexualidade e gravidez), mas aqui na escola não. (estudante da zona urbana).

É possível identificar no discurso dos estudantes da zona rural uma dificuldade em expressar opinião sobre a sexualidade ou sobre gravidez. Quando questionados sobre esses temas as respostas foram sempre curtas ou predominou o silêncio.

Pergunta: E aqui na escola já teve alguma situação de gravidez...alguma menina grávida na escola?

Resposta: Silêncio.

Pergunta: Se aparece uma menina grávida aqui na escola... tem alguma problema?

\section{Resposta: Nenhum...}

Apesar da gravidez na adolescência não constituir um fenômeno novo no cenário brasileiro ou mundial, a mesma vem assumindo, sobretudo nas últimas décadas, o "status" de problema social e de saúde, para o qual deve ser direcionada a atenção dos poderes públicos e da sociedade civil ${ }^{(18)}$.

D. Significados para acesso a equipamentos de saúde: "ausência de acolhimento e conforto humano" (urbano) e "ausência de qualidade de vida e acesso à saúde" (rural)

$A$ atenção à criança e ao adolescente é alvo de maior atenção desde a criação do ECA. No campo da saúde, 1989 foi o ano em que o Ministério da Saúde elaborou o Programa de Saúde do Adolescente (PROSAD), que tem como objetivo promover a saúde integral desse público, com abordagem multiprofissional, favorecendo o processo geral de seu crescimento e desenvolvimento, buscando reduzir a morbimortalidade e os desajustes individuais e sociais ${ }^{(4-5)}$.

A partir dos grupos de discussão foi possível identificar que, no contexto de análise, ainda existe muita dificuldade de acesso aos serviços de saúde pelos jovens e adolescentes, associada principalmente à ausência de atividades voltadas para esse grupo nos serviços de saúde e pela cultura de que os adolescentes não adoecem ou não são prioridade nos serviços. 
Então os postos de saúde no modelo do papel é muito bom, o governo tem um projeto muito bom, porém não é colocado em prática (estudante - zona urbana de VC).

Lá no Y onde eu moro, tem que agendar pra você ser atendido, não importa se você está muito doente ou não, agora para as mulheres grávidas lá é bom, têm exames, palestras. (estudante - zona urbana de VC).

Tem o planejamento familiar uma semana antes para quem vai se casar (estudante - zona rural de VC).

As ações propostas pelo PROSAD são de extrema importância para que seja alcançada no Brasil uma atenção/ assistência à saúde de qualidade e específica para os o público jovem, devido à singularidade desse grupo, e para que seja também garantida a equidade no acesso aos serviços de saúde, preconizado pelo SUS. No discurso dos jovens estudantes, os problemas de infraestrutura dos serviços são marcantes. que se apresentam.

E. Significados para família e filhos: "a importância de constituir família" (estudantes da área urbana e rural)

A formação familiar é mais comum entre os jovens com nível de escolaridade mais baixo: enquanto apenas 10\% dos jovens com nível superior são casados, 43\% dos jovens que tem até a $4^{\mathrm{a}}$ série do ensino fundamental já constituíram uma nova unidade familiar ${ }^{(12)}$. Para os participantes do estudo a educação é prioridade nessa etapa da vida, os filhos e a constituição de família são planos para o futuro.

Casar até que vai, mas filho por agora não (estudante zona urbana de VC).

Eu planejo assim, primeiro os estudos, penso em terminar o magistério e fazer faculdade de psicologia, e depois pensar em família, né. (estudante - zona urbana de VC).

A relação com a família foi relatada como boa e importante para os jovens. Outros estudos mostram que a família é a instituição em que os jovens mais confiam: $98 \%$ dizem que confiam e $83 \%$ que confiam totalmente na família ${ }^{(12)}$.

\section{F. Significados para emprego: "cobrança da sociedade e} dificuldade em conseguir o primeiro emprego"(urbano)

A dificuldade para conseguir o primeiro emprego é identificada claramente na fala dos estudantes e quando algum estudante relatou que possuía algum tipo de trabalho, referia-se a um trabalho informal.

A gente procura, mais não consegue nada. (estudante zona urbana de VC).

Bem, eu não trabalho, moro com meu pai e a minha mãe. (estudante - zona rural de VC).

Eu trabalho durante o dia, estudo de noite (...) sou autônomo, trabalho com transporte de estudantes dos povoados. (estudante - zona rural de VC).

Eles sempre pedem experiência, aí tem gente com experiência, só querem as pessoas que tem experiência. É bastante difícil, é quase impossível (estudante - zona urbana de VC).

O problema dos jovens em conseguir emprego é tema recorrente. Em estudo recente, $40 \%$, encontravam-se desempregados e, entre os que relataram alguma atividade de trabaIho, 30\%, estavam na informalidade, o que indica condições desfavoráveis de trabalho, com baixa remuneração e ausência de garantia de direitos trabalhistas, devido quase a totalidade desses jovens estarem na informalidade ${ }^{(12)}$.

\section{G. Significados para discriminação: "processos de constru- ção de identidades deterioradas" (estudantes da área urba- na e rural)}

Os jovens estudantes destacaram a discriminação por parte dos colegas como algo muito desagradável, que dificulta a interação social e o desenvolvimento escolar. Essa dificuldade não é enfrentada apenas pelos participantes do estudo, dados de pesquisas nacionais demonstram que $31,8 \%$ dos adolescentes já sofreu bullying ou algum tipo de discriminação ${ }^{(15)}$.

Eu já sofri, mais não foi aqui na escola não, pela minha voz (...) porque meus colegas ficavam rindo da minha cara, eu acho (...) ano passado eu passei por isso aqui na escola, aí...eu nasci assim e eu não tenho culpa, né. (estudante zona urbana de VC).

Aqui na escola não, quando eu tinha oito anos de idade eu tive uma doença, eu engordei muito e eu fiquei careca, aí na escola quando eu cheguei meus colegas me chamavam de gordinha, baleia, essas coisas, eu tive hidrocefalia [sic]. Isso não deixava de afetar um pouco... (estudante - zona urbana de VC).

Eu cheguei em uma loja pra comprar uma roupa, a moça não me atendeu, mal me atendeu, aí eu saí. Eu ia comprar, mas ela não me atendeu. (estudante - zona rural de VC).

\section{ANÁLISE E DISCUSSÃO}

Durante os trabalhos em grupo, foram feitas menções relativas à estratégia de Saúde da Família. A estratégia de Saúde da Família deve responder a uma nova concepção de saúde não mais centrada somente na assistência à doença, mas, sobretudo, na promoção da qualidade de vida e intervenção nos fatores que a colocam em risco, pela incorporação das ações programáticas de uma forma mais abrangente e do desenvolvimento de ações intersetoriais, com foco na família ${ }^{(19)}$.

Com as observações feitas, foi possível identificar que não existe uma programação específica para jovens e adolescentes nas Unidades de Saúde da Família. Os jovens e adolescentes 
aparentemente não são o público prioritário para ações de saúde. No período de observação dos serviços percebeu-se que os atendimentos realizados pelos jovens nas unidades de saúde são voltados não para a promoção da saúde, mas para consultas esporádicas, consulta pré-natal ou vacinação em campanhas. Nas unidades mencionadas pelos estudantes, não foram identificados grupos de educação em saúde para os esse público ou outras atividades de educação.

Ao questionar a um profissional de saúde o porquê dessa situação, o mesmo a justifica pela dificuldade em atrair para a unidade os adolescentes, demonstrando que os jovens não vêem a unidade de saúde como ambiente próprio para eles e que os profissionais não constroem estratégias para modificar essa realidade, o que reflete a atual formação do profissional de saúde, em cursos que ainda possuem currículos acadêmicos que não abordam ou abordam pouco a saúde do adolescente.

Faz-se necessário a implementação de ações que busquem a reorientação do processo de formação voltado para o desenvolvimento de competências e habilidades para o exercício de práticas e saberes capazes de dar respostas aos princípios propostos pela Reforma Sanitária e do SUS ${ }^{(20)}$. Para isso, os profissionais e as instituições de saúde precisam criar alternativas para garantir a atenção para diferentes públicos.

Excetuando a condição específica de gravidez, as adolescentes pouco utilizam os serviços de saúde, e quando o fazem, buscam apenas serviços curativos e não de prevenção ${ }^{(21)}$. Por outro lado, existem poucos serviços no Brasil disponíveis para atender especificamente as necessidades próprias dos adolescentes. Isso foi evidenciado durante os grupos de discussão com os adolescentes ao dialogar sobre filhos, família e gravidez. Os jovens e adolescentes mostraram que essa não é uma preocupação para o presente e que é necessário primeiro estudar e construir uma carreira no trabalho. Sentem que com a gravidez, os filhos e a família nesse momento da vida estarão deixando de aproveitar as oportunidades que o mundo lhes oferece, em especial em termos de escolarização e trabalho.

No caso das meninas, a perda de oportunidades atribui à gravidez grande importância simbólica por aumentar ainda mais as dificuldades de acesso a outros bens sociais, tais como educação, trabalho, remuneração e prestígio ${ }^{(22)}$. Isso revela que eles têm suas próprias demandas de saúde e que a oferta dos serviços de saúde não tem sido condizentes a elas.

\section{CONSIDERAÇÕES FINAIS}

A mudança do perfil de morbimortalidade da população, os hábitos não saudáveis na infância e juventude e suas implicações na vida adulta e o crescente número de morte de adolescentes e jovens por causas externas tem despertado a necessidade da criação de programas que sejam capazes de atender às demandas específicas dos adolescentes.

Construir alternativas para atrair os adolescentes e jovens aos serviços de saúde tem se revelado um grande desafio nas práticas de saúde devido às necessidades e expectativas particulares desse grupo. E apesar da comprovada relevância, a relação desse grupo com os serviços de saúde é pouco investigada no Brasil, mesmo sendo de extrema importância para orientar as ações de saúde voltadas para esse grupo populacional.

Nos resultados desta pesquisa fica patente que os jovens e adolescentes almejam um serviço de saúde onde eles se "encaixem", sintam-se parte do serviço e percebam que tal ambiente é voltado também para eles.

Em ambos os grupos de discussão realizados nesse estudo, nas áreas urbana e rural na cidade de Vitória da Conquista, foi possível identificar tanto a ausência do exercício efetivo da cidadania como evidências de que os jovens não tem tido o acesso pleno aos equipamentos sociais públicos e de saúde, o que se revela tanto no descompasso entre a idade escolar e biológica, na ausência de apoio institucional para os casos de gravidez ou mesmo no acesso a informação de qualidade. Percebe-se também um tom queixoso por parte dos estudantes, desejosos de melhores condições de vida. Como se constata na literatura, há políticas públicas elaboradas, idéias a serem desenvolvidas, mas os estudantes não as percebem no mundo de necessidades reais.

As respostas institucionais dadas às questões como gravidez, primeiro emprego ou na vida em comunidade nem sempre estiveram presentes ou foram adequadas. Percebe-se que há evidências e ausências do exercício efetivo de direitos e cidadania, tal qual preconizado no ECA e no PROSAD. É necessário que na elaboração de políticas públicas seja destacado que garantir acesso aos equipamentos de saúde é requisito básico para uma assistência eficiente e eficaz.

Além de elaborar programas é necessário que sejam criadas estratégias de inserção do adolescente no serviço para que de fato a política de assistência e promoção à saúde do adolescente, como proposto pelo PROSAD, seja integral em Vitória da Conquista no Sudoeste da Bahia.

\section{REFERÊNCIAS}

1. Ministério da Saúde: Área de Saúde do Adolescente e do Jovem. Marco Legal: Saúde, um Direito de Adolescentes. Brasília; 2005.

2. Conselho Nacional de Juventude. Política Nacional de Juventude: diretrizes e perspectivas. Brasília; 2006. p. 140.

3. IBGE. Síntese dos indicadores sociais: uma análise das condições de vida da população brasileira. Brasília; 2010. p. 149-90.
4. Ministério da Saúde. Serviço de Assistência a Saúde do Adolescente - SESAD. Normas de atenção à saúde integral do adolescente. Brasília; 1993. p. 8-11.

5. Ministério da Saúde. Coordenação da Saúde da criança e do adolescente - PROSAD: Programa Saúde do Adolescente - Bases programáticas. Brasília; 1996. p. 36.

6. IBGE. Censo 2010. Brasília; 2010. 
7. IBGE. [homepage na internet] Cidades - 2010. [acesso em 25 abr 2010]. Disponível em: < http://www.ibge.gov.br/ cidadesat/topwindow.htm?1>

8. Minayo MCS. O desafio do conhecimento: pesquisa qualitativa em saúde. 10. ed. São Paulo: Hucitec; 2007. p. 406.

9. Weller W. Grupos de discussão na pesquisa com adolescentes e jovens: aportes teórico-metodológicos e análise de uma experiência com o método. Educ Pesqui 2006;32(2):241-60.

10. Bardin L. Análise de Conteúdo. Lisboa: Edições 70; 1977. p. 226.

11. Helman C. Cultura, saúde e doença. 4. ed. Porto Alegre: Artes Medicas; 2003. p.408.

12. Abramo HW, Branco PM, organizadores. Retratos da Juventude Brasileira: Análises de uma pesquisa nacional. São Paulo: Fundação Perseu Abramo; 2004. p.448.

13. Ministério da Saúde. Violência Contra a Criança e o Adolescente: Proposta Preliminar de Prevenção e Assistência à Violência Doméstica. Brasília; 1997.

14. Minayo MCS e Souza ER. Violência para todos. Cad Saúde Pública 1993;9(1):65-78.
15. IBGE. Pesquisa Nacional de Saúde do Escolar - 2009. Rio de Janeiro; 2009.

16. Camargo $\mathrm{CL}$, Alves EL, Quirino, MD. Violência contra crianças e adolescentes negros: uma abordagem histórica. Rev Texto \& Contexto Enferm 2005;14(4):608-16.

17. Yazlle MEHD. Gravidez na adolescência. Rev Bras Ginecol Obstet 2006;28(8):443-5.

18. Heilborn ML, Salem T, Rohden F, Brandão E, Knauth D, Víctora C, et al. Aproximações socioantropológicas sobre a gravidez na adolescência. Horiz Antropol 2002;8(17):13-45.

19. Ministério da Saúde. Saúde da família: uma estratégia para a reorientação do modelo assistencial. Brasília; 1997.

20. Silva, MG et al. Processo de formação da(o) enfermeira(o) na contemporaneidade: desafios e perspectivas. Texto Contexto \& Enferm. 2010;19(1):176-84.

21. Carvacho IE, Mello MB, Morais SS, Silva JLP. Fatores associados ao acesso anterior à gestação a serviços de saúde por adolescentes gestantes. Rev Saúde Pública 2008;42(5):886-94. 